\title{
EL ENCOMIO DE HELENA Y LA RESPONSABILIDAD MORAL
}

\author{
JAVIER ECHEÑIQUE
}

\begin{abstract}
In his Encomium of Helen, Gorgias provides us with a variety of arguments in order to show that Helen was not to be held accountable for having eloped with Paris. The main thesis advanced in this article is that these arguments, despite their apparent diversity, are given a unitary structure by the concept of force, and by the analogy that Gorgias establishes between persuasion, the emotions, and sense-perception on the one hand, and this concept on the other. If this argument is successful, it shows that practically none of our actions are such that we are morally responsible for them. I discuss the cogency of this argument in connection with Aristotle's objections to it.
\end{abstract}

Un discurso tiene una pretensión teórica cuando manifiesta un cierto compromiso con la verdad intersubjetiva y con la argumentación racional como un modo de comunicarla. Sostengo esto precisamente porque hay ciertas razones que han prevenido que el famoso texto de Gorgias el Leontino, el Encomio de Helena, ${ }^{1}$ sea considerado como un discurso con pretensión teórica y en general, como una propuesta genuinamente filosófica. ${ }^{2}$ Para comenzar, existen razones internas al texto mismo. En Encomio $§ 5$ Gorgias sugiere que uno de los propósitos de su

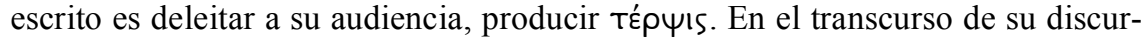
so, Gorgias también pareciera sostener (y algunos lo han visto así) que el discurso ( $\lambda$ óyos) es en sí mismo engañoso (Helena, en efecto, ha sido engañada por él, cf. ámatńбas, §8). Y como si fuera poco, Gorgias termina su Encomio de un modo sorpresivo, diciendo que lo ha escrito como una diversión para sí mismo

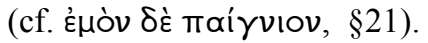

\footnotetext{
${ }^{1}$ Si hemos de confiar en la estimación de Porfirio (DK 82A2), el floruit de Gorgias el Leontino se sitúa en la octogésima olimpiada, es decir entre el año 460 y el 457 a. de. J., por lo que, aunque no sabemos su fecha exacta de nacimiento (fijada por la mayoría entre el 490 y el 485 a. de. J.), al menos sabemos que es mayor que Sócrates (circa 470).No sabemos exactamente cuando Gorgias escribió su Encomio.

${ }^{2}$ W. K. C. Guthrie, por ejemplo, llama al Encomio "a school exercise in rhetoric, sophistic in every sense" (GUTHRIE 1971, 50); Heinrich Gomperz habla del carácter "absolute Unsachlichkeit" y "rein Scherzhaft" del Encomio (GOMPERZ 1912, 12); y más recientemente W. J. Verdenius ha sostenido que de acuerdo a Gorgias, el discurso nunca es verdadero, sino que siempre involucra ómátᄁ, engaño (VERDENIUS 1981, 116-28).
} 
Estas afirmaciones levantan la sospecha de que el texto encaja llanamente con la definición socrática de la retórica que encontramos en el Gorgias de Pla-

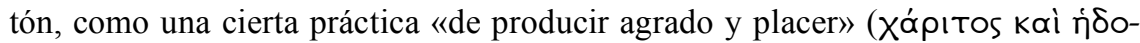

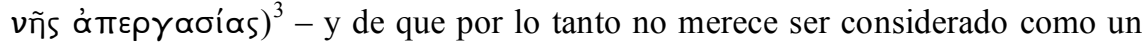
ejemplo genuino de argumentación filosófica. Existe también cierta evidencia externa, evidencia que deriva de otros textos de Gorgias mismo, que podrían llevarnos a una conclusión similar. En particular, en su opúsculo Sobre Lo Que No Es Gorgias pareciera argumentar que el lenguaje mismo es incapaz de comunicar la verdad. ${ }^{4}$

Estas razones, sin embargo, no sobreviven a un escrutinio detallado, y no son lo suficientemente firmes para negarle al Encomio una dimensión genuinamente teórica. En primer lugar, el contexto donde Gorgias menciona el deleite como uno de los propósitos de su discurso, muestra claramente que ese deleite es simplemente el deleite que conlleva el aprendizaje de algo nuevo, de un trozo de conocimiento: «decirle a los que saben las cosas que saben, aunque acarrea convicción, no aporta ningún deleite» ( $\$ 5)$. De modo que, lejos de poner en duda las pretensiones teóricas del Encomio, el deleite las presupone. En segundo lugar,

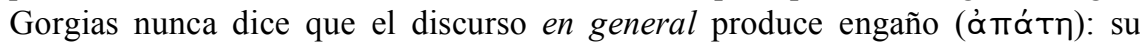
propósito (particularmente, en $\S 8$ ) es meramente mostrar que Helena podría haber sido engañada por un tipo de discurso particularmente persuasivo como el de Paris, para lo cual da otros ejemplos de discurso engañoso. El discurso verdadero no aparece aquí por la sencilla razón de que no es relevante. ${ }^{5}$ En tercer lugar, cuando Gorgias anuncia al final de su discurso que lo ha escrito como una diversión para sí mismo $(\$ 21)$, esto puede tomarse de muchas maneras. Podría por ejemplo tomarse esta afirmación como una declaración de modestia. Pero incluso si no fuese este el caso, ¿por qué pensar que la motivación de divertirse a uno mismo es incompatible con una pretensión teórica genuina?

Quizás la tesis gorgiana del opúsculo Sobre Lo Que No Es, según la cual el lenguaje mismo es incapaz de comunicar la verdad, sea la más problemática. Pero un examen medianamente detallado de esta tesis (MGX 980a19-b17 y $A M$ VII 83-85) revela que, lejos de versar sobre la incomunicabilidad de la verdad misma, versa sobre (1) la incomunicabilidad de la experiencia sensible, es decir, sensibilia como los colores, los sabores o los sonidos (lo cual sin duda le pareció atractivo al pirrónico Sexto Empírico, una de nuestras fuentes para reconstruir el texto). En sí misma, esta tesis no representa una negación de la verdad intersubjetiva, a menos que esté complementada por (2) una teoría empirista (al modo del

\footnotetext{
${ }^{3}$ Gorgias 462d-e1

${ }^{4}$ Para el opúsculo Sobre Lo Que No Es, tenemos dos fuentes: Una es Sexto Empírico (circa 200 d. de J.), en su libro Adversus Mathematicos (AM) VII, 65-85. Otra se encuentra en el Corpus Aristotelicus - las obras completas de Aristóteles - bajo el título De Melisso, Xenophane, Gorgia (MXG), 979a11$980 \mathrm{~b} 21$ (aunque ciertamente no fue escrito por Aristóteles mismo).

${ }^{5}$ Como bien señala MACDOWELL (1993), 13.
} 
empirismo lógico subjetivo ${ }^{6}$ ) acerca del significado de las palabras; una teoría según la cual todas las palabras de un lenguaje natural tendrían que ser explicables en última instancia en términos de una experiencia subjetiva posible o actual. Si la experiencia subjetiva es incomunicable, y esta misma experiencia proporciona la base semántica de nuestros lenguajes naturales, el lenguaje natural es esencialmente privado, y por ende no hay verdad intersubjetiva. Pero no puede discernirse ninguna tesis como (2) o algo que se le parezca en los textos relevantes.

Es a fin de cuentas en el Encomio mismo, cuando Gorgias nos anuncia la intención de su escrito (distinta de la motivación), donde se demuestra con claridad que las pretensiones que lo motivan son genuinamente teóricas, en tanto que están caracterizadas por el compromiso con la verdad intersubjetiva y con la argumentación racional:

Yo por mi parte deseo librar de la acusación a aquella que sufre de mala

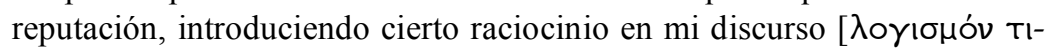
$v \propto T \tilde{\omega} \lambda$ ó $\gamma \omega$ Soùs], y habiendo delatado a los censuradores como impos-

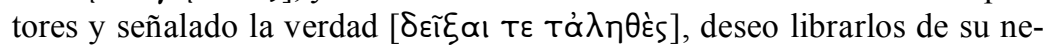
cedad. (Encomio $\$ 2^{7}$ )

Como Isócrates lo notó en su tiempo, ${ }^{8}$ el tema del Encomio de Helena no es en realidad encomiar o alabar a este personaje mítico, sino más bien defenderlo. El Encomio es, en realidad, una apología. Sabemos por la Iliada que Helena abandonó a sus hijos y a su esposo Menelao, rey de Esparta, para huir con Paris, príncipe de Troya, causando así la guerra entre aqueos y troyanos. Aparentemente, el acto fue tan deleznable y sus consecuencias tan abominables, que la discusión sobre la culpabilidad de Helena fue un tópico recurrente en la Grecia antigua.' Que Helena no siempre fue culpada por la tradición, lo muestra la Ilíada misma

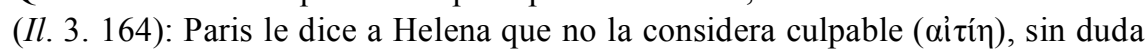
porque se consideraba que los dioses la habían elegido como un medio para

\footnotetext{
${ }^{6}$ El término ha sido acuñado por Anthony Flew. A. Flew hizo la famosa distinción entre empirismo lógico subjetivo y empirismo lógico objetivo. En el primer tipo de empirismo lógico, la experiencia está construida subjetivamente (como en Berkeley y Hume); mientras que en el segundo tipo la experiencia está construida en base a la concepción popular, del sentido común, de lo que significa ver, oír, sentir, aprender, sufrir, etc. Ver FLEW (1966), 50-51.

${ }^{7}$ Las traducciones son mías. Me ha basado en la edición de MACDOWELL (1993). También he cotejado la edición y traducción del Encomio por M. Bonazzi (BONAZZI 2011, 72-80).

${ }^{8}$ Isócrates en su Helena (14-15) critica a Gorgias por haber cometido el "pequeño descuido" de afirmar que este escrito es un encomio, en lugar de una apología.

${ }^{9}$ Para una visión más detallada de las opiniones en la antigüedad sobre la responsabilidad de Helena, véase TORDESILLAS (2008). El artículo también brinda un panorama amplio sobre el rol que juega la teoría gorgiana de la responsabilidad en la tradición posterior.
} 
llevar a cabo sus designios. Eurípides tocará también el tema en sus Mujeres Troyanas (914-1032) y en una obra tardía, Helena, exculpa al personaje al decir que no fue Helena quien huyó a Troya, sino su fantasma. A diferencia de estos relatos, sin embargo, la posición de Gorgias - según la cual Helena no es culpa-

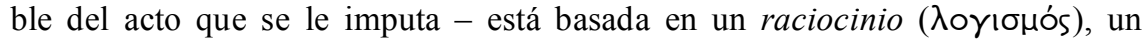

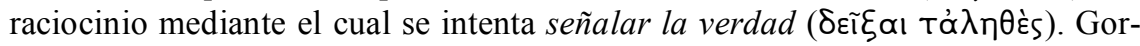
gias es enfático en esto.

Mi propósito en lo que resta de este artículo es precisamente demostrar que el Encomio de Helena exhibe un argumento riguroso, con pretensiones teóricas, y que por lo tanto ha de ser considerado como tal.

\section{II}

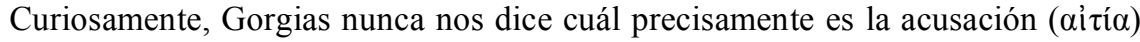
que se le hace Helena, y de la cual él pretende librarla: ¿Es abandonar a sus hijos y a su familia? ¿Acaso haber traicionado a su patria? ¿O quizás haber causado la guerra de Troya? Pero a medida que Gorgias va desarrollando sus argumentos va quedando claro que la respuesta a estas preguntas es irrelevante. La apología de Gorgias no se adecúa a la naturaleza particular del acto imputado a Helena y sus circunstancias específicas, sino que tiene una aplicación prácticamente universal. Quizás por esta razón Gorgias nunca se esfuerza por especificar el acto imputado a Helena. Los argumentos que Gorgias presenta dejan en claro que, si Helena es eximida de culpabilidad, todos lo estamos siempre (o casi siempre) respecto a todos nuestros actos.

En el transcurso del texto, Gorgias ofrece dos grupos de argumentos a favor de su tesis de que Helena ha de ser liberada de la acusación. Ambos grupos están anunciados al comienzo de la argumentación propiamente tal (he enumerado el texto para facilitar la referencia):

[1] O bien por los propósitos del Destino, las resoluciones de los dioses y los decretos de la Necesidad hizo $<$ Helena $>$ lo que hizo, [2] o bien fue capturada a la fuerza, o persuadida por las palabras, o cautivada por el Amor. (Encomio §6)

En lo que sigue de Encomio §6, es evidente que lo que Gorgias llama en [1] «los propósitos de la Fortuna», «las resoluciones de los dioses» y «los decretos de la Necesidad» son todos distintos nombres para una sola explicación del actuar de Helena. Es tentador para un lector contemporáneo pensar que esta explicación es una explicación determinista del actuar de Helena, así que llamémosla provisionalmente «alternativa determinista». La segunda alternativa propuesta por Gorgias, esta vez en [2], es una lista variada de excusas reconocibles por el sentido 


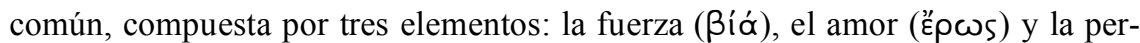
suasión $(\pi \varepsilon \imath \theta \omega ́)$. Llamémosla «alternativa de las excusas.»

En varios lugares del texto, Gorgias nos permite adivinar la contribución de estos dos grupos de argumentos a la cuestión sobre la responsabilidad de Helena. Respecto a la alternativa determinista, Gorgias nos dice que «si la causa ha de

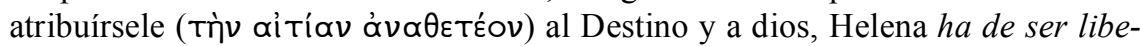

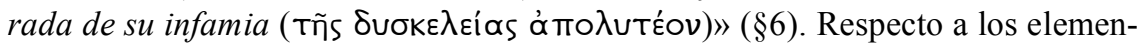
tos que constituyen la alternativa de las excusas, Gorgias nos dice que si alguno de estos se ha hecho efectivo, «sería razonable que $<$ Helena $>$ fuese objeto de

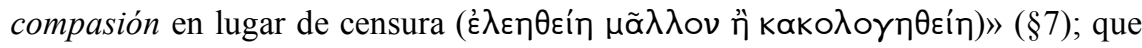

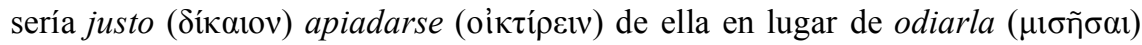

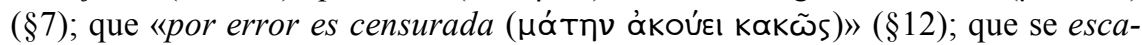

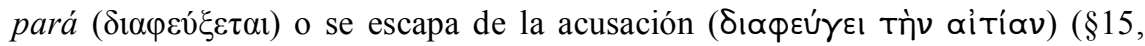
$\S 20)$. Todas estas expresiones muestran que la acusación que se le hace a Helena es la de haber cometido una falta moral, es decir, de haber actuado de un modo moralmente incorrecto. Una acusación o censura propiamente moral va generalmente acompañada de sentimientos morales como la indignación de la que habla Gorgias en $\$ 7$ - o al menos de la creencia de que dichos sentimientos serían apropiados. Por otro lado, la cancelación de dichos sentimientos morales o de la creencia en su validez da lugar al sentimiento de compasión del que habla Gorgias también en $\$ 7$. Lógicamente, sin embargo, sentir indignación moral o tener compasión hacia una persona muerta ya hace más de tres siglos no es algo natural, ni se aviene bien a la inmediatez de estos sentimientos o actitudes morales. Probablemente por eso es que Gorgias enfatiza que sería razonable o que sería justo apiadarse de Helena.

Gorgias tampoco nos dice cuáles son las condiciones (tanto del agente como del acto) que se requieren para que la censura o acusación moral a una persona que ha cometido una falta, sea justa o lícita. Pero queda claro que, cualquiera sean estas condiciones, él cree que la presencia de cualquiera de los factores en ambas alternativas tiene como consecuencia que una o más de estas condiciones no se cumplen, y que por ende censurar al agente no es justo. Ambos grupos de factores son tales que privan a cualquier acción $x$ (o a su agente) de la propiedad necesaria $F$, que hace de $x$ (o su agente) un objeto lícito de censura (y, presumiblemente, de alabanza).

El argumento que el texto en su totalidad desarrolla tiene entonces la siguiente estructura:

(i) Si la alternativa determinista es el caso, entonces el acto $x$ (o su agente) no tiene la propiedad $F$.

(ii) Si la alternativa de las excusas es el caso, entonces el acto $x$ (o su agente) no tiene la propiedad $F$. 
(iii) $<$ Es razonable (cíkós, §5) pensar que $>$ o bien la alternativa determinista es el caso, o bien cualquiera de los tres elementos en la alternativa de las excusas es el caso (o que ambas alternativas son el caso al mismo tiempo). ${ }^{10}$

(iv) Ergo: <es razonable pensar que> el acto $x$ (o su agente) no tiene la propiedad $F .^{11}$

Ahora bien, partamos con la alternativa determinista. Es tentador para el lector contemporáneo pensar que la alternativa determinista es para Gorgias la alternativa del determinismo nomológico, es decir, la tesis de que una descripción completa del estado del mundo en un instante $t$, junto con una descripción completa de las leyes naturales, implican lógicamente cualquier proposición verdadera acerca del mundo en cualquier estado posterior a $t$. El concepto de Destino o Necesidad en la alternativa determinista podría sugerir esto. Una lectura un poco más detallada del argumento de Gorgias en §6 pareciera sugerir, sin embargo, que la tesis determinista que Gorgias considera es más bien de índole teológica: parece ser el propósito ( $\pi \rho 0 \theta v \mu i ́ \alpha$, un estado eminentemente volitivo, no cognitivo) de Dios, y no las leyes de la naturaleza, lo que amenaza con determinar nuestros actos. El argumento que Gorgias ofrece, sin embargo, desilusiona al lector que espere encontrar aquí un argumento en base al determinismo divino, y de hecho a cualquier lector que espere encontrar aquí un argumento determinista. El argumento es el siguiente:

Pues lo natural es que lo más poderoso no sea coartado por lo menos po-

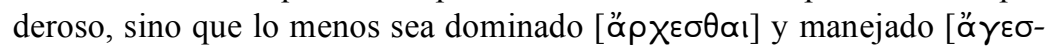
$\theta \alpha \mathrm{l}]<$ por lo más>, y que lo más poderoso domine, y lo menos obedezca. Dios, en efecto, es más poderoso que el ser humano tanto en fuerza [ßíâ], como en sabiduría [oopía y y en otros aspectos. Por lo tanto, si uno ha de

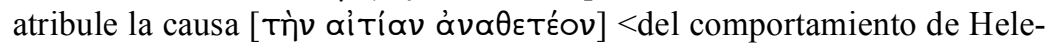
na> al Destino y a dios, Helena debe ser liberada de la infamia. Encomio $\S 6$

La alternativa determinista del Encomio no parece representar la amenaza que ha representado el determinismo (en cualquiera de sus variantes) para la tradición

\footnotetext{
${ }^{10}$ Aparentemente, esta premisa es un ejemplo claro de lo que D. G. Spatharas llama 'apagogic reasoning', es decir, donde cada una de las razones es tratada separadamente, y ninguna de ellas resulta o presupone la precedente (SPATHARAS 2001, 406). Parte de mi propósito es mostrar que, si bien ésta es la estructura superficial de la premisa, un nivel más profundo de análisis muestra que todas las razones aquí expuestas dependen fuertemente de aquella relativa a la fuerza o constreñimiento.

${ }^{11}$ Ésta pareciera ser en efecto la estructura argumentativa que Gorgias quiere darle al texto. Sin embargo, quedará en claro al final que la alternativa de las excusas (y el elemento de las pasiones y la percepción) es prácticamente siempre el caso - de modo que la alternativa determinista es a fin de cuentas redundante.
} 
filosófica, desde los atomistas en adelante: en pocas palabras, para dicha tradición el determinismo, cualquiera sea la versión que de él se adopte, implica de algún modo un futuro único y cerrado cuyo desenvolvimiento no depende de nosotros. El argumento que Gorgias ofrece para la primera alternativa, sin embargo, muestra que el determinismo del Encomio tiene una relevancia en relación al fenómeno de la responsabilidad que depende completamente de otros conceptos: conceptos derivados, en última instancia, de excusas comunes provenientes del sentido común, y de la analogía que pueda establecerse entre dichos concep-

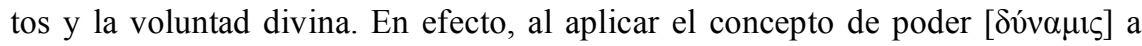
los portadores tradicionales del determinismo, Gorgias se esfuerza por asimilar la alternativa determinista a una excusa común y corriente, como lo es la coerción o la fuerza.

Otro modo de ver esto, es notando que Gorgias no parece argumentar del siguiente modo: «(i) Si dios y el Destino (ambos son aquí sinónimos) son la causa (última) del actuar de Helena, y (ii) un agente es sólo (moralmente) responsable de sus actos cuando es la causa (última) de sus actos, entonces (iii) Helena no es (moralmente) responsable de su actuar». Contrariamente a lo que podría pensar un determinista, desde la perspectiva gorgiana el hecho de que Dios sea la causa (última) del actuar de Helena no parece ser por sí mismo suficiente para librar a Helena de la responsabilidad de su actuar. Lo que pareciera ser suficiente es una caracterización del tipo de causalidad que Dios ejerce sobre el acto de Helena, a saber, una causalidad de índole violenta o forzosa.

Al final de este artículo quiero sugerir una interpretación más benevolente del argumento «determinista» (o más bien, «proto-determinista») de Gorgias. Por ahora, es útil hacerse la pregunta: ¿No es posible que Gorgias esté asimilando el origen causal (último) de nuestros actos en dios, con la fuerza o constreñimiento [ßía, óvó $\gamma \mathrm{k} \eta]$ - y que además esté justificado en hacer esta asimilación?

\section{III}

El segundo grupo de argumentos, la alternativa de las excusas, es ciertamente el aporte más significativo de Gorgias al problema de la responsabilidad moral. El resto del Encomio consiste en una explicación de porqué la presencia de cada una de las excusas mencionadas, tomadas cada una por separado, eximirían a

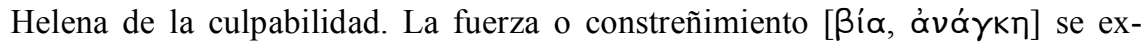

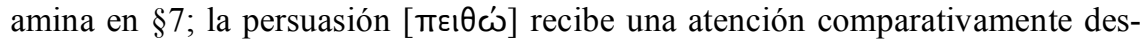
mesurada, pues se analiza de $\S 8$ a $\S 14$ (prácticamente un tercio del texto); y

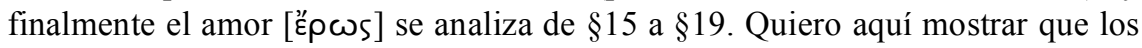
tres grupos de argumentos basados respectivamente en la fuerza, la persuasión, y el amor, están íntimamente relacionados entre sí, en tanto que (1) dependen de un presupuesto básico, original de Gorgias, acerca de la fuerza o constreñimien- 
to, y (2) en el caso (derivado) de la persuasión y el amor, dependen de la cercanía que pueda establecerse en última instancia entre el fenómeno del amor y la persuasión por un lado, y dicho presupuesto por el otro. ${ }^{12}$ (No quiero aquí sugerir que no puedan encontrarse otros argumentos en el texto, sino más bien que su médula está en el argumento que a continuación presento). Finalmente, quiero mostrar que Gorgias no se limita al caso del amor y de la persuasión, sino que extiende su argumento a otras emociones, a nuestros estados motivacionales, y más fundamentalmente, a nuestras percepciones y las acciones basadas en ellas. Esta extensión tendrá como consecuencia que prácticamente todas nuestras acciones son involuntarias, y por ende libres de culpa.

Partamos con el punto (1). Cuando Gorgias trata el fenómeno de la fuerza o el constreñimiento en $\S 7$, no explica qué es lo que entiende por estos conceptos, ni aquella propiedad de dichos fenómenos en virtud de la cual los actos forzados o constreñidos son puestos fuera del alcance de la censura. Es razonable, empero, pensar que la propiedad en cuestión es la externalidad, es decir, el hecho de que el origen o la causa (la $\alpha i \tau i ́ \alpha$, el mismo término para «acusación») de la acción sea, en última instancia, externo al agente. Después de todo, la definición más próxima a Gorgias que encontramos del fenómeno de la fuerza o constreñimiento, es la de Aristóteles, quien define la acción forzada o constreñida en parte como aquella cuyo origen es externo al agente (cf. ह̌ $\xi \omega \theta \varepsilon v$, Ethica Eudemia 1224a23, b7, b11, Ethica Nicomachea 1110a1; દ̇v Toĩs Ė́Tós, Ethica Nicomachea 1110b2-3). Para entender bien porqué la externalidad es tan importante en el argumento de Gorgias, y cómo es introducida en la discusión, es necesario pasar al punto (2) mencionado en el parágrafo anterior.

\footnotetext{
${ }^{12}$ Así interpretado el argumento de Gorgias, no ya como una serie de alternativas independientes sin relación la una con la otra (ver nota 9 supra) sino más bien como un solo argumento unitario, éste adquiere mucho más fuerza, y entra en conflicto directo con interpretaciones, como la reciente de Michael Gagarin, basadas en una construcción de las alternativas como alternativas separadas entre sí y completamente independientes. Gagarin sostiene, en base a los siguientes argumentos, que el propósito del argumento del Encomio no es persuadir al lector: (i) De las cuatro causas propuestas por Gorgias, sólo los dioses y la fuerza humana son agentes que eximen de responsabilidad, tradicionalmente, y por ende Gorgias podría haber logrado un caso persuasivo si se hubiera basado sólo en estas dos; (ii) Gorgias sin embargo trata estas dos causas - las más persuasivas - brevemente, y discute en cambio las otras dos posibilidades, el discurso persuasivo y el amor, ninguna de las cuales puede ser considerada persuasivamente como un elemento que exime de culpabilidad; (iii) el retrato del discurso persuasivo ofrecido por Gorgias, además, enfatiza su asociación siniestra con el engaño, las drogas y la magia, lo que haría que los lectores y oyentes del Encomio fuesen aún menos comprensivos con Helena; (iv) y por si fuera poco, Gagarin argumenta que el amor era tradicionalmente la causa de crímenes atroces cometidos por mujeres (GAGARIN 2001, 281). Los argumentos (iii) y (iv) - la numeración es mía - son poco convincentes, y los argumentos (i) y (ii) están basados justamente en la premisa que yo pretendo negar, según la cual las cuatro 'alternativas' son argumentos independientes, que brindarían cada uno por sí mismo, plausibilidad a la conclusión sobre la inocencia de Helena.
} 
Después de la fuerza o el constreñimiento, Gorgias trata el fenómeno de la persuasión. Es evidente que las siguientes dos premisas son esenciales para el argumento que Gorgias ofrece en base al poder de la persuasión:

(A) La persuasión obtiene su relevancia como excusa o factor exculpatorio en la medida en que se logre establecer una cercanía suficiente entre ella y el fenómeno de la fuerza o constreñimiento.

En $§ 12$, por ejemplo, Gorgias nos dice que si el elogio alcanzó a Helena, lo hizo

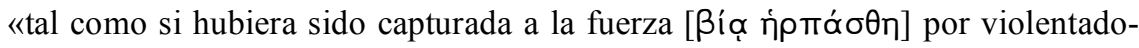
res», y luego nos dice que aunque la persuasión no sea, en estricto rigor, el mismo fenómeno que el constreñimiento propiamente tal [ává $\gamma \mathrm{k} \eta$ ], «tiene el mismo poder, pues el discurso, el persuasor del alma, constriñe [ウ่vá $\gamma \kappa \propto \sigma \varepsilon]$ al alma».

(B) La cercanía que pueda establecerse entre la persuasión y el fenómeno de la fuerza o constreñimiento, depende a su vez de la cercanía que pueda establecerse entre la operación de las pasiones y dicho fenómeno, pues la persuasión opera directamente en las pasiones, y son las pasiones en última instancia las que poseen la propiedad relevante de la fuerza o el constreñimiento.

Que la persuasión opera directamente en las pasiones, y que éste es el aspecto de la persuasión que le interesa más a Gorgias, se ve claramente en el parágrafo introductorio al argumento basado en la persuasión, §8: el discurso persuasivo «es capaz de detener el miedo y de quitar el dolor, de provocar alegría y de acrecentar la compasión». En $\S 9$ se establece además que el discurso persuasivo afecta al alma con sentimientos específicos como el temor, las ansias o la compasión. Y en el último parágrafo del argumento, §14, Gorgias nos dice que «unos argumentos producen malestar, otros agrado, otros producen temor, otros producen coraje en los oyentes». Es natural colegir de todos estos pasajes que, cuando Gorgias nos dice que el discurso persuasivo fuerza al alma «tanto a obedecer las cosas dichas como a aprobar las cosas hechas» (\$12), dicha obediencia y aprobación se logran mediante el efecto de las pasiones, así como el discurso del litigio que en $\$ 13$ se dice deleitar a la mayoría y, en virtud de ese deleite (que es un arte), convencerla.

De vital importancia para el argumento de Gorgias es entonces pasar al tema de las pasiones, y establecer que las pasiones son las portadores de aquella propiedad $F$, común al constreñimiento, que hace de las acciones motivadas por ellas objetos ilícitos de censura. No es entonces una coincidencia que Gorgias pase inmediatamente a tratar el fenómeno de las pasiones. Y una premisa esencial al argumento basado en las pasiones que nos ofrece el Encomio, resulta ser, 
precisamente, la premisa sobre la externalidad, es decir, sobre el origen externo de las pasiones o, en general, de los estados motivacionales:

Las cosas que vemos no tienen la naturaleza que nosotros queremos que

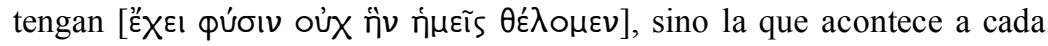
una de ellas. Además, mediante la vista el alma es moldeada inclusive en sus modos de comportarse. En efecto, cuando hay cuerpos hostiles y una organización hostil de bronce y hierro listos para la batalla, la una defensiva y la otra exhibiendo proyectiles, si la vista ve esto inmediatamente se alarma y alarma al alma, de modo que la gente huye poseída por el pánico ante el peligro futuro, como si ya existiese. (Encomio $§ 15-16$ )

El mismo argumento que Gorgias aduce respecto al temor, se aplica también a afecciones como el placer y el dolor, y a estados eminentemente motivacionales

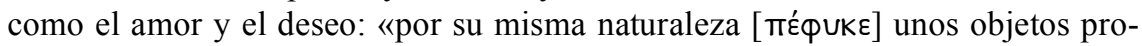
ducen dolor a la vista y otros apetencia. Y muchas cosas producen en muchos amor y apetito por varias circunstancias y cuerpos» $(\S 18) .{ }^{13}$

El uso deliberado del concepto de naturaleza [фúoı)] en ambos pasajes tiene

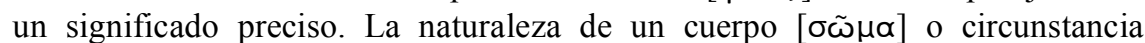
[ $\pi \rho \tilde{\alpha} \gamma \mu \alpha$, también «acto»] está conformada por aquellas propiedades del cuerpo o la circunstancia que no dependen de nosotros, ni derivan de nuestro modo de relacionarnos con ellos: son, en este sentido, propiedades externas a nosotros. El argumento de Gorgias es que las pasiones y estados motivacionales, como el amor, el deseo, o el temor, tienen precisamente un origen externo en la percepción de cuerpos o situaciones externas al sujeto, que por sus mismas propiedades naturales (por ejemplo, la belleza de Helena) gatillan dichas pasiones y estados motivacionales al ser percibidos. El poder coercitivo del drama o la poesía, por ejemplo, deriva precisamente de este aspecto de las pasiones, como Gorgias

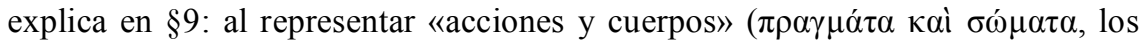
mismos términos que Gorgias emplea en $§ 18$ ) en situaciones tales que estimulan pasiones específicas, la poesía se nutre en última instancia de la asociación regular entre dichas situaciones y sus correspondientes pasiones ya existente en la vida mundana. ${ }^{14}$

Tomando como caso paradigmático entonces el fenómeno de la fuerza o constreñimiento, cuya propiedad fundamental es la externalidad, Gorgias puede construir una teoría causal acerca del origen de las pasiones y estados motivacio-

\footnotetext{
${ }^{13}$ Es interesante notar que en ambos pasajes, en éste y el de Encomio §15-16 supra, se hace referencia exclusivamente a la vista como medio de interacción entre el mundo físico y las emociones del alma. Este punto ha sido magistralmente estudiado por Charles P. Segal en relación con su tesis de que en Gorgias (y en particular en el Encomio) encontramos una relación recíproca e incuestionada entre el alma y el mundo material (SEGAL 1962).

${ }^{14}$ Para una interpretación contemporánea de la teoría de Gorgias sobre la poesía y la tragedia, véase BARNES (1982), 365-366.
} 
nales, según la cual las acciones gatilladas por dichas pasiones y estados son involuntarias en virtud de su origen externo:

Objeto externo $o$ con propiedad $G(o G) \rightarrow$ Percepción de $o G \rightarrow$ Pasión específica $\rightarrow$ Acción involuntaria en relación a $o$

Por ejemplo: hay en el campo de batalla una organización hostil o alarmante (propiedad $G$ ) de armamento. Yo veo el armamento y distingo la propiedad $G$. La propiedad $G$ gatilla una pasión determinada (yo me alarmo) y la pasión gatilla una acción (yo huyo). Es necesario en este punto notar una cierta ambigüedad en Encomio \$15-16 (ver supra). En estricto rigor, Gorgias no expresa claramente que la influencia causal de la percepción de un objeto externo con una cierta cualidad evaluativa (y por ende potencialmente motivacional) en la acción, está necesariamente mediada por una pasión o emoción. Es posible que Gorgias piense (y el texto permite esta interpretación) que dicha influencia de la percepción de una propiedad evaluativa en el objeto pueda ejercerse directamente en la acción, sin mediación de las pasiones.

Objeto externo $o$ con propiedad $G(\mathrm{o} G) \rightarrow$ Percepción de o $G \rightarrow$ Acción involuntaria en relación a $o$.

Como mostraré en la siguiente sección, decidir entre ambas interpretaciones no es importante, pues el problema de la tesis gorgiana se encuentra presente en ambas versiones.

Es de notar eso sí que el caso de la persuasión, y de otras actividades discursivas (como la poesía) que constriñen, depende en última instancia del constreñimiento ejercido por las pasiones del modo establecido en el primer esquema:

Persuasión o representación de que $o$ es $G \rightarrow$ Pasión específica $\rightarrow$ Acción involuntaria en relación a $o$

(Las flechas representan la relación de causa-efecto). Es evidente, por lo tanto, que pese al programa inicial de Gorgias, donde el amor figuraba como la pasión particular que tendría un rol protagónico en el argumento, lo que ha hecho Gorgias en efecto es desarrollar un argumento cuya conclusión es que prácticamente todas nuestras acciones - independientemente de si están motivadas por el amor, o por la persuasión, o por la fuerza - son involuntarias, al tener en última instancia un origen causal externo al agente, a saber, un origen en la percepción de una cierta propiedad evaluativa ('alarmante', 'bella', etc.).

Ahora bien, si el argumento de Gorgias es el que hemos sugerido, y si tiene alguna pretensión teórica (como yo creo que la tiene), no debería ser difícil encontrar alguna referencia a dicho argumento en la literatura posterior relacionada con el tema de la responsabilidad. Mi impresión es que de hecho encontramos 
una referencia a dicho argumento en la literatura filosófica posterior a Gorgias, y la encontramos en un texto de Aristóteles. Aristóteles se encarga, por lo demás, de refutarla. En la siguiente sección mi propósito es rastrear esta dialéctica, para así poder ponderar con más precisión el valor filosófico de la tesis gorgiana.

\section{IV}

La tesis de Gorgias expuesta en la sección anterior resurge en la Ethica Nicomachea $(E N)$ de Aristóteles, del siguiente modo:

Supongamos que alguien dijera que lo placentero y lo bello son forzosos

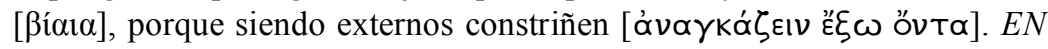
1110b9-10.

Aunque es imposible establecer con certeza si Aristóteles tiene a Gorgias en mente, los argumentos que Aristóteles ofrece en contra de esta tesis tocan la médula del problema presente en la teoría de Gorgias expuesta en la sección anterior, según la cual la mayoría de nuestras acciones, afecciones y estados motivacionales, son el producto de la fuerza en la medida en que derivan en última instancia de un origen externo, que Gorgias identifica con la percepción de una propiedad evaluativa externa como la belleza de Helena.

En EN 1110b9-15 Aristóteles ofrece una serie de argumentos en contra de esta tesis, pero hay uno de ellos que tiene un interés particular, porque atañe al problema de fondo presente en la tesis gorgiana: «es absurdo» - dice Aristóteles - «culpar a lo que está afuera de nosotros en lugar de a uno mismo por dejarnos cazar tan fácilmente por ello» (1110b13-14). En otras palabras, el objeto propio de la censura es la deficiencia del carácter moral de uno, y no el objeto externo que estimula la acción.

Un modo interesante de elaborar en más detalle esta crítica al argumento gorgiano, es poniendo en cuestión el supuesto fundamental en el que está basado, a saber:

Supuesto: El hecho de que un objeto o evento $x$ sea percibido como $G$ (bello, placentero, etc.) por un sujeto $S$, depende exclusivamente de las características intrínsecas a $x$ y extrínsecas a $S$ - es decir, características de $x$ que no dicen relación al carácter individual de $S$ - sin importar la cualidad $G$ en cuestión.

Éste es, claramente, el supuesto fundamental detrás de la tesis de Gorgias. En jerga aristotélica (que en parte coincide con la de Gorgias mismo) el supuesto sería que $x$ aparece a cada sujeto $S$ del modo en que aparece (por ejemplo, como

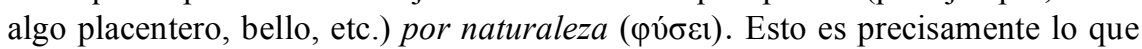


dice Gorgias: «Las cosas que vemos no tienen la naturaleza que nosotros queremos que tengan, sino la que acontece a cada una de ellas» (Encomio §15).

Es posible inferir el argumento de Aristóteles en contra del supuesto mencionado, en base a $E N 1114 \mathrm{a} 31-21$. El modo en que $x$ aparece a cada sujeto S, no es siempre «por naturaleza», sino que a veces es relativo al carácter de $\mathrm{S}$ (ómoĩós

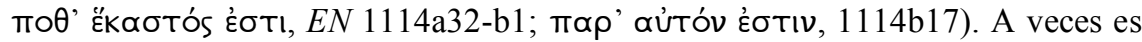

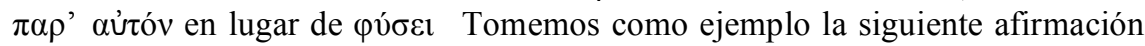
gorgiana:

Cuando hay cuerpos hostiles y una organización hostil de bronce y hierro listos para la batalla, la una defensiva y la otra exhibiendo proyectiles, si

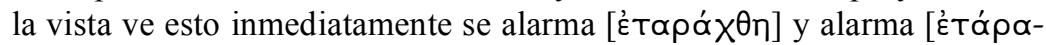
$\xi \varepsilon]$ al alma. (Encomio $§ 16)$

Aquí Gorgias claramente asume que la percepción de un objeto hostil como alarmante es como la percepción de un objeto circular (por poner un ejemplo). La objeción de Aristóteles consiste en notar que 'alarmante', a diferencia de 'circular', denota una relación particular entre el sujeto percipiente y el objeto: el sujeto percipiente mantiene una actitud de rechazo hacia el objeto, y el hecho de que el objeto sea alarmante o no, depende en última instancia de que el sujeto percipiente mantenga o no esta actitud hacia él. Como consecuencia, el objeto en tanto alarmante no es 'algo externo', ni es alarmante 'por naturaleza'.

Si queremos hacerle justicia a Gorgias, sin embargo, hay que notar que él tiene quizás un contra-argumento a la mano. En efecto, Gorgias pareciera argüir que si uno pudiera establecer que el mismo objeto aparece alarmante a todos sus percipientes (del modo en que probablemente Helena les pareció bella a todos los griegos), entonces un objeto en tanto alarmante es, después de todo, una fuente externa de lo que su percepción estimula. El argumento, quizás, rezaría así: si la generalización es correcta, ha de haber una ley de la naturaleza según la cual ciertas propiedades naturales de un objeto causan invariablemente una cierta actitud hacia dicho objeto bajo ciertas condiciones. ${ }^{15}$ Incluso si 'alarmante' denota una relación entre el objeto y el percipiente, dichas propiedades naturales (por ejemplo, la organización del bronce y el hierro en el ejemplo de Gorgias) no denotan dicha relación. Si todos, bajo condiciones 'normales', perciben dichas propiedades naturales como 'alarmantes' (es decir, mantienen la actitud de rechazo al percibirlas), si bien dicha regularidad puede deberse a la naturaleza humana, o a las propiedades naturales mismas, o a una interacción de los dos,

\footnotetext{
${ }^{15}$ Esta postura intermedia que le atribuimos aquí a Gorgias recuerda inevitablemente a la tesis de David Hume en su Of the Standard of Taste, según la cual, pese a que la belleza y la deformidad no son propiedades de los objetos, existen ciertas cualidades en los objetos, que están diseñadas por naturaleza para producir esas sensaciones particulares.
} 
hay disponible de todos modos un sentido de «externo» («externo al carácter de los percipientes individuales») que brinda plausibilidad a la afirmación de que el objeto en tanto alarmante constituye una fuente externa de todo aquello que su percepción estimula.

Ahora bien, si la regularidad que hemos señalado se debe en efecto a la naturaleza humana, las percepciones correspondientes podrían ser perfectamente consideradas como externas al carácter del percipiente. Pero Gorgias necesita más que este triunfo para alcanzar la conclusión que desea, a saber, eximir a Helena de su presunta responsabilidad por un acto. Para lograr este objetivo, Gorgias necesita argumentar, no solo que (1) la percepción que $S$ tiene de $x$ en tanto alarmante es externa al carácter de $S$, sino también que (2) el hecho de que $S$ se alarme es externo a su carácter, o que (2') el hecho de que S actúe en base a dicha percepción es externo a su carácter. La objeción que naturalmente se ofrece, en este respecto, es que la transición lógica de (1) a afirmaciones más contundentes como (2) o (2') es injustificada.

Aristóteles piensa, por ejemplo, que la persona valiente puede incluso percibir, debido a su condición natural de ser humano, una organización dada de escudos y lanzas como alarmante, e incluso podría aceptar que por ende dicha percepción es externa del modo en que hemos sugerido: pero el valiente no actúa en base a dicha percepción, ni se siente alarmado por ella. Sus acciones son por lo tanto plenamente suyas, pese a los intentos de Gorgias de demostrar lo contrario.

La tesis fundamental de este artículo ha sido que el grupo de argumentos que hemos denominado «la alternativa de las excusas» es en realidad un solo argumento que corre desde Encomio $§ 7$ hasta casi el final del texto, en $\S 19$, y que dicho argumento es filosóficamente interesante, y constituye la contribución más significativa de Gorgias al problema de la responsabilidad moral.

Quisiera terminar con una sugerencia. Nuestra reconstrucción de la alternativa de las excusas, según la cual el elemento exculpatorio fundamental para Gorgias es la existencia de una causa externa de nuestros actos, un elemento que deriva fundamentalmente del fenómeno de la fuerza, pero que la percepción de la que dependen nuestros actos (y nuestras pasiones) también manifiestan; esta reconstrucción, abre una posibilidad para interpretar la alternativa determinista que examinamos en la Sección II. Vimos aquí que, según Gorgias, "si uno ha de atribule la causa <del comportamiento de Helena $>$ al Destino y a dios, Helena debe ser liberada de la infamia» (Encomio §6), sólo porque el tipo de causalidad divina se asemeja a la causalidad que se ejerce por la fuerza (pues los actos forzados no son censurables). Si el argumento es interpretado de este modo, estaría basado en una analogía casi pueril. Pero si ser una causa última, externa de $x$ implica, en virtud de la definición misma de fuerza ( $\beta i ́ \alpha)$ que $x$ ha sido causado 
a la fuerza - y que por lo tanto no es censurable - podemos entonces considerarlo seriamente, pues habría ya no una mera analogía pueril entra la causalidad ejercida por Dios por sobre nuestros actos por un lado, y el fenómeno de la fuerza por el otro, sino más bien una conexión conceptual. Y no sólo eso, sino que la alternativa determinista pasaría entonces a formar parte integral del argumento más general desarrollado en la alternativa de las excusas. ${ }^{16}$

Javier Echeñique

Pontificia Universidad Católica de Chile javiechenique@yahoo.es

\footnotetext{
${ }^{16}$ Vale la pena notar que esta interpretación puede resolver además un problema con el argumento de la alternativa determinista, discutido por Robert Wardy: "there is plentiful evidence, at least for earlier times, that Greeks tolerated an overdetermined scheme for the explanation of behaviour; one and the same act might be attributed to both a human agent and the intervention of a supernatural being, without divine influence necessarily freeing the human agent from the consequences of his or her action" (WARDY 1996, 34). Si aquella propiedad en virtud de la cual la alternativa determinista exime a Helena de culpabilidad es la misma propiedad en virtud de la cual la alternativa de las excusas exime a Helena de culpabilidad, entonces el problema notado por R. Wardy no surge para Gorgias.
} 


\section{BILIOGRAFIA}

BARnes, J. (1982), The Presocratic Philosophers, London \& New York, Routledge.

BonAzZI, M. (2011), I sofisti, Milano, Rizzoli

FLEW, A. (1966), Hume's Philosophy of Belief, London, Thoemmes Press

Gagarin, M. (2001), Did the Sophists Aim to Persuade?, "Rhetorica" 19, 275 291.

GOMPERZ, H. (1912), Sophistik und Rhetorik, Berlin, Teubner.

GuthriE, W. K. C. (1971) The Sophists, Cambridge, Cambridge University Press.

MacDowell, D. M. (1993), Gorgias: Encomium of Helen, New York, Bristol Classical Press.

SEgal, Ch. P. (1962), Gorgias and the Psychology of Logos, "Harvard Studies in Classical Philology" 66, 99-155.

Spatharas, D. G. (2001) Patterns of Argumentation in Gorgias, "Mnemonsyne" 54, 393-408.

TORDESILlas, A. (2008), Gorgias et la question de la responsabilité d'Hélène, F. Alesse - F. Aronadio - M.C. Dalfino - L. Simeoni - E. Spinelli (eds.), Anthropine sophia. Studi di Filologia e storiografia filosofica in memoria di Gabriele Giannantoni, Napoli, Bibliopolis, 45-54.

Verdenius, W. J. (1981), Gorgias Doctrine of Deception, en G. B. Kerfeld (ed.), The Sophists and their Legacy, "Hermes Einzelschriften" 44, 116-28.

WARDY, R. (1996), The Birth of Rhetoric: Gorgias, Plato and their Successors London \& New York, Routledge. 